\title{
La evolución de la autoridad parental en Francia y su incidencia en las facultades y deberes del progenitor no custodio*
}

\author{
Gonzalo Ruz Lártiga**
}

\begin{abstract}
RESUMEN
Desde la década de los 70 que Francia ha revolucionado su Derecho de familia en general, y la regulación de la autoridad parental en particular, mediante la oportuna reacción y adaptación a los cambios de sus modelos sociofamiliares, lo que se ha evidenciado en una evolución legislativa marcada por decenios de cambios relevantes. Desde el fin de la era patriarcal, con la eliminación de la noción de patria potestad y su reemplazo por la de autoridad parental, hasta la consagración de la residencia alternada como modo general de ejercicio de la autoridad parental para padres separados o divorciados cualquiera sea la filiación de los bijos (as), en menos de medio siglo esta "revolución francesa del derecho de familia" ha sabido conciliar las facultades y deberes de los progenitores no custodios en relación con el cuidado y educación de los bijos otrora entregados al padre o madre custodios que actuaban revestidos de un gran poder de exclusión en las decisiones importantes de la vida de los menores.
\end{abstract}

Autoridad parental - progenitor no custodio - residencia alternada

\section{The evolution of parental authority in France with regard to the powers and duties of noncustodial parent}

\begin{abstract}
Since the early 70's that France has revolutionized its family law in general, and the regulation of parental authority in particular through the timely reaction and adaptation to changing socio-family models, which has been demonstrated in a legislative developments marked by decades of relevant changes. Since the end of the patriarchal era, with the elimination of the notion of parental authority and its replacement by parental authority, until the consecration of alternating residence as a general mode of exercise of parental authority to divorced or separated
\end{abstract}

* El presente artículo forma parte de la investigación titulada: "Facultades y deberes del padre no custodio", Proyecto Fondecyt $\mathrm{N}^{\circ}$ 1150454, 2015-2016, en el que el autor es coinvestigador.

** Abogado. Doctor en Derecho privado, U. d'Aix-Marseille, Francia. Profesor asociado de Derecho civil y comercial Escuela de Derecho (Santiago), Facultad de Ciencias Jurídicas y Sociales, Universidad Santo Tomás, Chile. Correo electrónico: gonzaloruz@santotomas.cl

Artículo recibido el 30.8.2016 y aceptado para su publicación el 10.7.2017. 
parents whatever filiation of children, in less than balf a century. This "French revolution of family law" has managed to reconcile the powers and duties of noncustodial parents on the care and education of former child delivered to the parent or guardian mother coated exclusion great power in important decisions of life of children.

Parental authority - noncustodial parent - alternate residence

\section{INTRODUCCIÓN}

$\mathrm{L}$ a tensión entre la ley y la realidad (modelos sociales) a la que la primera está llamada a aplicarse es permanente. Leyes que tardan en regular o reconocer una realidad indesmentible versus leyes que se anticipan a lo que la realidad no percibe o requiere aún regular: las unas, leyes reaccionarias; las otras, leyes revolucionarias. Esta tensión, debido al carácter cíclico de nuestra humanidad caracteriza, en uno de sus aspectos, el Derecho de familia.

En Francia, en 1792, la Asamblea Nacional que hacía su primera aparición, votaba una ley revolucionaria ${ }^{1}$, que introducía el divorcio por acuerdo mutuo (invocando la libertad de los individuos y la igualdad de los cónyuges), la que, derogada poco tiempo después con la promulgación del Código de Napoleón (1804), no se restablecería en términos amplios ${ }^{2}$ sino hasta 1975 . En este último año se dicta la Ley $\mathrm{N}^{\circ} 75-617^{3}$, que se promulgaba con mucho retraso, cuando la realidad obligaba a los cónyuges a recurrir a mecanismos jurídicos desviados para alcanzar sus objetivos producto de esta tardanza legislativa. En ese contexto, la misma realidad había exigido cinco años antes la reacción legislativa para poner término a otra regulación que no se adecuaba a la realidad, esta vez, en relación con uno de los efectos de la filiación, la patria potestad.

En efecto, en 1970 se dictaba una ley ${ }^{4}$ que confería a las madres la misma autoridad que detentaban los padres sobre los hijos, marcando de paso un cambio de nomenclatura

\footnotetext{
${ }^{1}$ Ley promulgada el 20 de septiembre de 1792 que dispone la laicización de los estados civiles y la autorización del divorcio.

${ }^{2}$ No debe quedar la idea que el Code derogó el divorcio por consentimiento mutuo, lo que hizo fue restringirlo notoriamente. En efecto, el Code de Napoléon de 1804 contenía en el Libro I, el Titre VI "Du Divorce" que, en su Capítulo III " $D u$ divorce par consentement mutuel" no lo admitía para el cónyuge menor de 25 años y para la cónyuge menor de 21 años (art. 275) y siempre que el matrimonio hubiere durado al menos dos años (art. 276) y nunca cuando el matrimonio hubiere durado más de 25 años o la cónyuge tuviera más de 45 años de edad (art. 277), entre varios otros requisitos. El divorcio, bajo todas sus formas, fue derogado efectivamente bajo la época de la Restauration (ley de 8 mayo de 1816) y no fue restablecido sino en la Troisième République (ley de 27 de julio de 1884).

${ }^{3}$ Ley $\mathrm{N}^{\circ} 75-617$ promulgada el 11 de julio de 1975 sobre reforma del divorcio.

${ }^{4}$ Ley $\mathrm{N}^{\circ} 70-459$ promulgada el 4 de junio de 1970 relativa la autoridad parental y publicada en el JORF el 5 de junio de 1970 (entrada en vigor desde el $1^{\circ}$ de enero de 1971).
} 
para afirmar el fin de la era patriarcal: desaparecía la puissance paternelle (potestad paterna o patria potestad $)^{5}$ y hacía su aparición la noción de autoridad parental ${ }^{6}$.

Desde ese último tercio del siglo XX, Francia ha tardado menos tiempo en reaccionar y adaptar las reglas de la autoridad parental a los cambios de sus modelos sociofamiliares $^{7}$, lo que se refleja en su evolución legislativa que bien podría llamarse revolución legislativa en algunos aspectos. En efecto, los avances de la autoridad parental en Francia han estado directamente relacionados con la (r) evolución de la vida familiar a partir de esta data y, en particular, a partir de la década de 1970. Esta década, como se dijo, comenzaría con un gran reconocimiento del principio de igualdad en la titularidad de

\footnotetext{
${ }^{5}$ Sin embargo, ya en los trabajos preparatorios del Code, se discutía que los derechos entregados al padre o a la madre no lo eran sino en el contexto que su ejercicio tuvieran a la vista el desarrollo físico y moral del niño (V. Locré, J.-G., La Législation civile, commerciale et criminelle de la France, ou Commentaire et complément des Codes français, T.7, Treuttel et Wurtz Libraires, París, 1827, p. 52. V. también Savatier, R., L'Art de faire de lois. Bonaparte et le Code civil, Dalloz, París, 1927, pp. 30-31). La regla en materia de autoridad parental estaban contenidas en el Code en el Título IX, De la puissance paternelle, donde el art. 371 establecía que el niño, de cualquiera edad, debía honor y respeto a su padre y madre. En los dos artículos siguientes hacía la diferencia entre titularidad y ejercicio de la patria potestad: El art. 372, disponía que el menor quedaba sumido a la autoridad de ambos hasta su mayoría de edad o su emancipación; mientras que el art. 373 señalaba que solo el padre ejercía esta autoridad durante el matrimonio. En la redacción del Code de 1804, se incorporaron las modernizaciones de la época a las rigideces romanas de la patria potestas, lo que constituyó un derecho bastante novedoso. Por ejemplo, la solicitud de divorcio por consentimiento mutuo debía acompañarse necesariamente de un acuerdo de los cónyuges en donde se decidiera cuál de ellos tendría el cuidado personal de los hijos (art. $280 \mathrm{~N}^{\circ}$ 1) o en la regulación de los arts. 302 y 303 , ubicados en materia de los efectos del divorcio (culpable) y referidos a la tuición, guarda o cuidado personal de los hijos, que establecían, el primero, que los niños serían confiados al esposo que había obtenido el divorcio, salvo que el tribunal, a solicitud de la familia, o de un comisario del Gobierno, dispusiera, para el mayor beneficio de los menores, que todos o algunos de ellos fueran confiados al cuidado del otro de los esposos o incluso a una tercera persona. Por el segundo de los artículos nombrados, se prescribía que -cualquiera que fuere la persona a quienes se confiara el cuidado personal del hijo- el padre y la madre conservarían respectivamente el derecho de vigilar la educación y mantenimiento de sus hijos, siendo obligados a contribuir en ellas en proporción a sus facultades. Bajo la aplicación del Código de Napoleón la Corte de Casación, poniendo en ejercicio la creación pretoriana del derecho tan característica en Francia, dicta una de las sentencias más célebres en derecho de familia francés (Veuve Jaumes c. Jac du Puget, Cass. Civ. 8 juillet 1857. V. Capitant, H., Les grands arrêts de la jurisprudence civile, $9^{\mathrm{e}}$ éd., (por F. Terré e Y. Lequette), Dalloz, Paris, 1991, pp. $237-$ 244), donde la Corte reinterpreta los artículos que fundan el fallo de la Corte de Apelaciones de Montpellier estableciendo que la potestad paterna no es absoluta ni puede ejercerse sin control alguno, abusivamente, y lo sería cuando compromete el interés de los hijos.

${ }^{6}$ Para una revisión de la evolución histórica hasta la dictación de la Ley $\mathrm{N}^{\mathrm{0}}$ 70-459 recomendamos: Deleury E., Rivet M. y Neault J.-M. "De la puissance paternelle à l'autorité parentale: Une institution en voie de trouver sa vraie finalité", en Les Cabiers de Droit (Revista de Derecho de la U. de Laval), vol. 15, $\mathrm{N}^{\circ} 4$, 1974, pp. 779-870 y la síntesis de los profesores Malaurie y Aynès (Malaurie, Ph. y Aynès, L., La famille, $4^{\mathrm{e}}$ éd., Défrenois. Lextenso Editions, París, 2011, pp. 600-606). Para una revisión de la evolución histórica después de la dictación de la Ley N $70-459$ recomendamos: Terré, F. y Fenouillet, D., Les personnes. La famille. Les incapacités, $7^{\mathrm{e}}$ éd., Dalloz, Paris, 2005, pp. 989-1015.

${ }^{7}$ V. Brunetti-Pons, C., "L'exercice de l'autorité parentale face au pluralisme familial" en Dialogue $2004 / 3, N^{\circ} 165$, p. 7-22. En menos de cinco décadas se han producido en Francia cinco grandes reformas (una en cada década) al derecho de la autoridad parental, lo que refleja un tiempo de adaptación de la regla a la realidad imperante bastante satisfactoria.
} 
la autoridad parental por ambos progenitores, aunque también con grandes vacíos en relación con el ejercicio de la misma, que solo se comenzarían a llenar con la consagración de los primeros pilares del principio de la coparentalité, en la década de los 80 .

La década de los 90 debutaría con un evento mayor en Francia: la entrada en aplicación de la Convención de Nueva York o Convención de Derecho del niño, lo que exigiría una nueva adaptación del Código Civil francés y donde la Convención, a pesar de un inicio bastante difícil en cuanto a su aplicación jurisprudencial, cambiaría definitivamente el eje de atención del derecho de familia hacia la noción proteiforme de interés superior del menor ${ }^{8}$, que terminará de imponer el ejercicio conjunto de la autoridad parental como dogma9 .

El primer decenio del nuevo milenio (años 2000 a 2010) se verá marcado por una modificación del concepto mismo de autoridad parental, mientras que el segundo decenio (2010 hasta la fecha) se caracterizará por la consagración de la noción de résidence alternée, como máxima expresión del ejercicio de la autoridad parental, como uno de los mecanismos que aseguran un efectivo y concreto ejercicio conjunto de este derecho-función. En concreto, se postula que Francia ha logrado una evolución progresiva y constante mediante reacciones coherentes, rápidas y oportunas, de su derecho de la autoridad parental en armonía con la revolución de las formas de constituir familias, lo que ha significado una verdadera revolución en la naturaleza jurídica de la autoridad parental, incidiendo notablemente en el equilibrio del ejercicio de las facultades y deberes de ambos progenitores, al introducir mecanismos o instrumentos jurídicos variados, que han equilibrado las prerrogativas y deberes del no custodio, en cuatro etapas bien marcadas, agrupadas en dos momentos claves: por un lado, el inicio de la evolución del derecho de la autoridad parental, que se puede visualizar en las reformas del último trimestre del siglo pasado (I) y, por otro lado, en la consolidación de esa evolución materializada en los dos primeros decenios del presente siglo (II).

\section{UNA EVOLUCIÓN DE LA AUTORIDAD PARENTAL QUE SE INICIA A PARTIR DEL ÚlTIMO TRIMESTRE DEL SIGLO XX}

El punto de partida de la verdadera revolución del derecho contemporáneo francés de los efectos de la filiación, en particular en lo que se refiere a la evolución de las prerrogativas y deberes entre progenitores e hijos, puede situarse con la Ley $\mathrm{N}^{\circ} 70-459$ de 4 de junio de 1970 relativa a la autoridad parental. Previo a este hito el Código Civil francés distinguía claramente entre la titularidad de la patria potestad y el ejercicio de la misma. La primera, correspondía a ambos progenitores hasta la mayoría de edad o la

${ }^{8}$ V. Dumortier, T., "L'intérêt de l'enfant: les ambivalences d'une notion 'protectrice'”, en La Revue des droits de l'homme [En línea], $\mathrm{N}^{\circ} 3$, 2013, pp. 2-13. Disponible en www.revdh.revues.org/189. Consultado el 05.08.2016.

${ }^{9}$ La expresión la emplea Bruggeman, M., "L'excercice en commun de l'autorité parental après séparation en France”, en Osaka University Law Review, N 58, febrero 2011, pp. 93-106. 
emancipación del menor, según lo disponía el art. $372^{10}$; mientras que por el art. $373^{11}$, se disponía que solo el padre ejercía esta autoridad durante el matrimonio. En la situación de los progenitores no unidos en matrimonio la titularidad y el ejercicio de la patria potestad era unilateral.

\section{Desde una autoridad parental en función de la igualdad parental hasta el establecimiento de los primeros pilares de la coparentalidad}

La ley de 1970, como ya se ha avanzado, confirió a las madres la misma autoridad que detentaban los padres sobre los hijos, imponiendo un cambio de nomenclatura para afirmar el fin de la era patriarcal al desaparecer toda mención a la patria potestad o puissance paternelle, para ser reemplazada por la noción de autorité parentale.

El cambio de nociones (patria potestad por autoridad parental) era el reflejo de una nueva visión de las relaciones jurídicas entre los progenitores y sus hijos. Desde la entrada en vigencia del Código Civil de Napoleón, en 1804, bajo la influencia de uno de sus comisionados Jean-Jacques-Régis de Cambacérès, la mujer casada tenía en el seno de la familia un rango inferior, la incapacitaba en términos casi absolutos, lo que la hacía inapta para tomar decisiones respecto de su persona y todavía menos en relación con los hijos, decisiones todas que se encontraban subordinadas al marido como "jefe de familia". La puissance paternelle le aseguraba al marido la exclusividad de la autoridad sobre su mujer (puissance marital), así como sobre los hijos (patria potestas), excluyendo a esta en toda decisión. La noción de autoridad parental consagrará, entonces, la igualdad de poderes y deberes del padre y madre sobre los hijos.

Un cambio "simbólico", en palabras de los profesores Gouttenoire y Fulchiron ${ }^{12}$, aunque no menos determinante, desde que el neologismo, siguiendo a los profesores Malaurie y Aynès ${ }^{13}$ y a los profesores Terré y Fenouillet ${ }^{14}$, marcaría un "doble cambio de perspectiva": por un lado, la palabra autorité, subrayaría que el poder soberano dejaba su lugar a una autoridad concebida como un complejo de derechos y deberes; y, por el otro, la palabra parentale destacaba que esta autoridad pertenecía por igual al padre y a la madre que, en principio, la ejercerían en común. El paso fue paradigmático ${ }^{15}$ y

${ }^{10}$ Art. 372 (anterior a la Ley 70-459): Il reste sur leur autorité jusqu'à sa majorité ou son émancipation.

${ }^{11}$ Art. 373 (anterior a la Ley 70-459): Le père seul exerce cette autorité durant le mariage.

${ }^{12}$ Gouttenoire, A., y Fulchiron H., "Autorité parentale", en Dalloz, Répertoire de droit civil, 2005 (actualizado a enero de 2016), $\mathrm{N}^{\circ} 14$.

${ }^{13}$ Malaurie y Aynès, op. cit., p. 599. Para estos autores, por un lado, la palabra puissance evocaba un poder ilimitado en beneficio de su titular, mientras que la palabra autorité sugiere una función que se atribuye en el interés de otro; y por el otro, la palabra paternelle demostraba un monopolio del padre, mientras que parentale sugiere una igualdad de padre y madre.

${ }^{14}$ Terré y Fenouillet, op. cit., pp. 962-963.

${ }^{15}$ No en términos kuhntianos (Kuhn, Thomas S., The Structure of Scientific Revolutions, The University of Chicago Press, Chicago, $2^{a}$ ed., 1970) o acerca de la idea de la naturaleza revolucionaria del cambio científico, sino más bien en los términos que emplea el Diccionario de la Real Academia Española en su primera acepción, es decir, como sinónimo de ejemplar. 
respondía, por cierto, a un cambio cultural y moral de la época que exigía adecuaciones de la ley a los modelos sociales que se venían imponiendo ${ }^{16}$.

En efecto, se trataba, a no dudarlo, de un reconocimiento -en derecho- de la mujer en su función maternal, una suerte de promoción jurídica de la madre que, sin embargo, mantenía la igualdad solo en el papel, pues, en los hechos, el ejercicio de la autoridad parental seguía, en lo patrimonial, en manos del padre como administrador legal de los bienes del hijo (a) ${ }^{17}$ y solo en el contexto de la familia matrimonial no disuelta.

En efecto, es posible señalar que a partir de la ley de 1970 la disociación entre titularidad y ejercicio de la autoridad parental desaparecía y se igualaba la situación de los progenitores. Así lo pretendió reflejar el texto del art. 371-2 del Code ${ }^{18}$ que dispuso, a partir de esta ley, por su inciso primero, que "la autoridad parental pertenecía al padre y a la madre para proteger al niño en su seguridad, salud y moralidad”, mientras que por el inciso segundo se sentaba que "Ambos tienen en relación a él, el derecho y deber de residir con el (la) menor, de vigilarlo y de educarlo”.

A partir de la ley de 1970, entonces, la autoridad parental pasará a ser considerada, por un lado, como un conjunto de poderes condicionados por deberes que perseguían un fin: la protección del niño (a); y, por el otro, como una autoridad que debía ser ejercida concertadamente, en un pie de igualdad, por el padre y la madre. Esto, insistimos, en la letra de la ley y, reiteramos, para los casos de familias matrimoniales no disueltas. En los casos de divorcio, separación o tratándose de hijos no matrimoniales, el modelo que primaba era el del ejercicio unilateral de la autoridad parental entregada, generalmente, al progenitor custodio con la correlativa restricción de las prerrogativas y deberes del padre no custodio ${ }^{19}$.

En concreto, la ley de 1970 constituyó un paso adelante para las uniones matrimoniales no disueltas y sus hijos, pero cuando estas uniones se disolvían la desigualdad entre progenitores seguía imponiéndose con soluciones recurrentes: manteniendo el statu quo ante, en caso de acuerdo, o recurriendo al juez de familia para decidir en caso de conflicto, quien confiaba generalmente la entrega en exclusiva del cuidado personal de

${ }^{16}$ Ciertos autores sugieren hoy dar un nuevo paso en la nomenclatura y emplear la expresión responsabilité parentale como lo sugiere desde 1979 el Consejo de Europa (Recomendación 974/1979, relativa a Carta Europea de Derechos del Niño). El legislador francés de la Ley No 2002-305 promulgada el 4 de marzo de 2002, lo discutió, pero decidió finalmente no incorporar la noción y mantener la de autoridad parental.

${ }^{17}$ Ciertos temperamentos, sin embargo, serían introducidos luego, por ejemplo, por una ley de 11 de julio de 1975 (Ley $\mathrm{N}^{\circ}$ 75-617) respecto del divorcio, que instauraría una suerte de presunción de poder para la madre para ejecutar los actos corrientes o usuales de administración del menor (art. 372-2 Code civil: " $A$ l'égard des tiers de bonne foi, chacun des époux est réputé agir avec l'accord de l'autre, quand il fait seul un acte usuel de l'autorité parentale relativement à la personne de l'enfant". . Solo en 1985 (Ley No 85-1372 de 23 de diciembre de 1985) hará desaparecer estos vestigios de desigualdad.

${ }^{18}$ Art. 371-2. "L'autorité appartient aux père et mère pour protéger l'enfant dans sa sécurité, sa santé et sa moralité. Ils ont à son égard droit et devoir de garde, de surveillance et d'éducation."

Este artículo armonizará con el art. 203 del mismo Code relativo a los derechos y obligaciones entre cónyuges que señalaba: Les époux assument ensemble la direction morale et matérielle de la famille. Ils pourvoient à l'éducation des enfants et préparent leur avenir.

${ }^{19}$ V. $\mathrm{n} 5$. 
los hijos a la madre, mientras el padre se mantenía como titular exclusivo de la autoridad parental en su faz patrimonial ${ }^{20}$. Tratándose de hijos no matrimoniales, la situación era más desigual aún, pues la madre era la única y exclusiva titular de la autoridad parental incluso cuando el padre había reconocido al hijo $(a)^{21}$. Unido a lo anterior, el contenido que la ley daba a la autoridad parental (residencia, cuidado y educación), que luego sería suprimido por una ley del año 2002, constituyó una fórmula mal percibida desde un principio por la doctrina, y así como lo señalan los profesores Terré y Fenouillet, desde un comienzo fue objeto de críticas ${ }^{22}$.

Una nueva serie de evidencias que demostraban más cambios socioculturales en Francia (aumento de los divorcios, explosión de las uniones no matrimoniales y crecimiento exponencial de los hijos no matrimoniales), trajo consigo la necesidad de igualar en derechos a las categorías de hijos sin importar su filiación, lo que traería como consecuencia una nueva desadaptación del Derecho vigente, provocando la reacción legislativa en materia de autoridad parental en el decenio siguiente.

En efecto, 1987 marcaría la penúltima década del siglo XX con la dictación de una ley ${ }^{23}$ que consagraría los pilares del principio de la coparentalité o responsabilidad

${ }^{20}$ Art. 372-1 (nacido de la Ley 70-459). Si les père et mère ne parvenaient pas à s'accorder sur ce qu'exige l'intérêt de l'enfant, la pratique qu'ils avaient précédemment pu suivre dans des occasions semblables leur tiendrait lieu de règle.

A défaut d'une telle pratique ou en cas de contestation sur son existence ou son bien-fondé, l'époux le plus diligent pourra saisir le juge des tutelles qui statuera après avoir tenté de concilier les parties.

${ }^{21}$ Art. 374 (nacido de la Ley 70-459). Sur l'enfant naturel, l'autorité parentale est exercée par celui des père et mère qui l'a volontairement reconnu, s'il n'a été reconnu que par l'un d'eux.

Si l'un et l'autre l'ont reconnu, l'autorité parentale est exercée en entier par la mère. Le tribunal pourra, néanmoins, à la demande de l'un ou de l'autre, ou du ministère public, décider qu'elle sera exercée soit par le père seul, soit par le père et la mère conjointement, auxquels les articles 372 à 372-2 seront alors applicables, comme si l'enfant était un enfant légitime.

Esta solución era una alternativa adaptada a la época, no solo como consecuencia de la iniciativa legislativa de promover a la mujer en su rol de madre, sino más bien como una manifestación del movimiento sociológico del derecho que encabezaría el Decano Carbonnier (Carbonnier, J., Sociologie juridique, Librairie Armand Colin, Paris, 1972, 320 pp.).

${ }^{22}$ Terré y Fenouillet, op. cit. (n. 14), p. 972; citando a Simler, Ph., "La notion de garde de l'enfant (sa signification el son rôle au regard de l'autorité parental)", en RTD civ. (Revue Trimestrielle de Droit Civil), 1972 , p. 685 y ss. En efecto, señalan Terré y Fenouillet que "para algunos autores la noción de cuidado (surveillance) no era más que un corolario de la residencia (garde) y educación. Para otros, la residencia aparecía más como una prerrogativa general que permitía asegurar la función parental que como una prerrogativa distinta; para otros todavía encerrar o limitar la autoridad parental en esa numeración reducía la riqueza de los poderes y prerrogativas conferidas a los padres en el interés del niño (a)". Por esa razón la ley de 4 de marzo de 2002 al redefinir la autoridad parental concentraría esta alrededor de sus funciones: protección y educación; aunque dejaría todavía subsistente la determinación de la residencia (garde) del menor como una prerrogativa específica.

${ }^{23}$ Ley N $\mathrm{N}^{\circ}$ 87-570 promulgada el 22 de julio de 1987 acerca del ejercicio de la autoridad parental, llamada también Loi Malburet sur l'autorité parentale conjointe. Para un estudio de la doctrina de la época recomendamos la lectura de: Legeais, R., "Les ajustements égalitaires de l'autorité parentale”, en Defrénois, 1988, art. 34243; Morançais-Demeester M,-L., y Nicolas-Maguin, M.-F., "Pouvoirs du juge et volonté des parents dans l'exercice en commun de l'autorité parentale prévu par la loi du 22 juillet 1987", en Dalloz, 1988, Chronique, pp. 307 y ss.; Monéger, "L'exercice conjoint de l'autorité parentale. Aperçu d'une réforme", en RDSS (Revue de droit sanitaire et sociale), 1987, pp. 699 y ss. 
parental compartida cuya regla se traduciría en que, en todas las hipótesis de separación de padres unidos previamente en matrimonio, la autoridad parental sería ejercida en común o por uno de los padres, pero siempre en función del interés del menor. Como se advierte, con este paso adelante se estaba manteniendo el statu quo ante para después de la separación de las uniones matrimoniales, es decir, si los padres otrora casados ejercían la autoridad parental en conjunto, el mismo estado de cosas se mantenía, en principio, en caso de ruptura, a menos que el juez interviniera y excluyera a uno de los progenitores en favor del otro. En caso de acuerdo entre progenitores, el estado anterior de cosas se mantenía sin intervención judicial.

El legislador francés comienza, además, a definir más precisamente los contornos de la noción de garde (nuestro "cuidado personal” para aproximarla de algún modo), con el fin de reemplazarla por la simple obligación, vía reconocimiento judicial, de que el o los menores tuvieran una residencia habitual en casa de algunos de los padres ${ }^{24}$. Al mismo tiempo, en caso de ejercicio unilateral de la autoridad parental, el legislador va a reequilibrar, en principio también, los derechos del padre no custodio definiendo el droit de surveillance o derecho de vigilancia de este, prerrogativa que estará íntimamente ligada a la responsabilidad civil del padre no $\operatorname{custodio}^{25}$ y a su participación en la

${ }^{24}$ Esta modificación se infiere de la redacción de los arts. 374 inciso $3^{\circ}$ y 287 del Code civil.

El art. 374 del Código Civil francés bajo la redacción de la Ley 87-570 señalaría lo siguiente: "La autoridad parental es ejercida sobre el hijo natural por aquel padre o madre que lo haya voluntariamente reconocido. Si ambos lo han reconocido, la autoridad parental es ejercida por la madre (inc. $1^{\circ}$ ). La autoridad parental puede ser ejercida en común por ambos padres si así lo solicitan conjuntamente ante al juez de tutela (inc. $2^{\circ}$ ). A solicitud del padre, de la madre o del Ministerio Público, el juez de asuntos familiares puede modificar las condiciones de ejercicio de la autoridad parental y decidir que ella será ejercida sea por uno de los padres, sea en común por el padre y la madre; El juez indicará en cada caso el padre en cuyo domicilio tendrá el menor su residencia habitual (inc. $3^{\circ}$ ). El juez de asuntos matrimoniales puede siempre acordar un derecho de visitas y vigilancia al padre privado del ejercicio de la autoridad parental (inc. $4^{\circ}$ ). En caso de ejercicio conjunto de la autoridad parental, los arts. 372-1 y 371-2 son aplicables como si el menor fuese un hijo legítimo (inc. $5^{\circ}$ )".

El art. 287 del Código Civil francés bajo esta misma redacción dispondrá que: "Según lo exija el interés de los menores, la autoridad parental es ejercida sea en común por ambos padres después de que el juez haya comprobado su aceptación, sea por solo uno de ellos. En caso de ejercicio en conjunto de la autoridad parental, el juez designará al padre con quien el menor tendrá su residencia habitual”.

${ }^{25}$ En materia de responsabilidad civil de los padres por el hecho del menor (aunque evidentemente trasciende el objeto del presente trabajo), no se puede dejar de mencionar la reticencia de la Corte de Casación francesa en extender el ámbito de aplicación del art. 1384 inciso $4^{\circ}$ del Código Civil francés al padre en cuyo domicilio no se ha fijado la residencia habitual del menor a pesar que la titularidad y el ejercicio de la autoridad parental la detenten ambos progenitores. Una doctrina constante se confirma en un fallo de 29 de abril de 2014 ( $\mathrm{N}^{\circ}$ 13-84.207) por cuya virtud la sala penal de la Corte de Casación reitera el principio en el que la responsabilidad de pleno derecho de los padres de un menor no está ligada al ejercicio de la autoridad parental sino a la fijación de su residencia habitual, pues la aplicación del art. 1384 inciso $4^{\circ}$ del Código Civil incumbe efectivamente solo al padre en cuyo domicilio el menor tiene su residencia habitual, por lo que poco importa saber si el otro padre ejerce conjuntamente o no la autoridad parental o si se beneficia de un derecho de visita y alojamiento. La circunstancia que se le pueda hacer efectiva su responsabilidad civil personal por el desinterés en el menor después de la separación conyugal no puede ser considerado por el juez para determinar la responsabilidad civil de pleno derecho que resulta del artículo citado. 
educación del menor ${ }^{26}$. En fin, tratándose de hijos (as) no matrimoniales, sea que los padres estuviesen o no viviendo juntos, se dispuso que ambos seguían siendo titulares de la autoridad parental y que podían ejercerla en común, siempre que hubiese acuerdo entre ellos, lo que debían formalizar por escrito ante el juez. En caso de desacuerdo, la ley seguía (por razones prácticas) privilegiando a la madre en el ejercicio de la autoridad parental y facultando al juez para conferir al padre no custodio un derecho de visitas y de vigilancia.

\section{El proceso de adaptación de la autoridad parental en función del interés del niño(a)}

La década de los 90 comenzaría con un evento mayor en Francia: la entrada en aplicación de la Convención de Nueva York o Convención de Derechos del Niño ${ }^{27}$, lo que exigiría una nueva adaptación del Código Civil.

${ }^{26} \mathrm{El}$ droit de surveillance, que comprende el derecho de vigilar la crianza y educación del menor se analiza en Francia como un derecho de ser informado, de ser consultado y de proponer, pero en ningún caso como un derecho de exigir o de prohibir, los que permanecen como atributos exclusivos de la patria potestad. Resulta interesante traer a colación la respuesta que el Ministro de Justicia de la época daría a una pregunta escrita formulada en una sesión del Senado (V. Application du droit de surveillance du père, 9e législature, Question écrite N 11799 de M. Pierre-Christian Taittinger, publicada en el JO Sénat el 27/09/1990, p. 2077). El Sr. Taittinger consulta cómo puede traducirse en la práctica el derecho de vigilancia del padre, cuando la autoridad parental es conjunta, pero la residencia habitual del menor se ha fijado en el domicilio de la madre. La respuesta del Ministro de Justicia (Respuesta publicada en el JO Sénat del 29/11/1990, p. 2545) es la siguiente: "En la hipótesis en que se ha decretado el ejercicio en común de la autoridad parental, cada padre se mantiene responsable, de la misma manera, de la educación del menor. Las decisiones deberán entonces ser tomadas conjuntamente por el padre y la madre, conforme lo disponen los arts. 372-1 et 372-2 del Código Civil. El acuerdo de los padres, a pesar de su separación, constituye la manifestación del ejercicio de la autoridad parental. En consecuencia, el padre en cuya casa el menor resida no podrá tomar decisiones importantes sin contar con el acuerdo previo de su excónyuge. En estas condiciones el legislador no ha previsto, de una manera particular, el derecho de vigilancia en provecho del padre cuyo hijo reside en el domicilio de su excónyuge. Sin embargo, puede sostenerse que el tribunal que resuelve sobre el divorcio o sobre algún conflicto originado después de su pronunciamiento, organiza, a solicitud de los padres, las modalidades de ejercicio de ese derecho". Disponible en https:/www.senat.fr/questions/ base/1990/qSEQ900911799.html. Visitado el 12.08.2016.

${ }^{27}$ Adoptada y abierta a la firma, ratificación y adhesión de los Estados por la Asamblea General de las Naciones Unidas mediante Resolución No 44/25 de 20 de noviembre de 1989, entrada en vigor en Francia el 2 de septiembre de 1990.

Acerca de la recepción de la Convención de los Derechos del Niño en Francia: V. Bureau, D., "De l'application directe en France de la Convention de New York du 26 janvier 1990 sur les droits de l'enfant", en RCDIP (Revue critique de droit international privé), 2005 p. 679; Dekeuwer-Défossez, F., "L'application de la Convention de New York sur les droits de l'enfant" (note sous Civ. 1er, 10 de marzo y 2 de junio de 1993), en Dalloz 1994. Sommaire 34; y "La Convention internationale des droits de l'enfant: quelles répercussions en droit français?", en CRDF (Rev. Cahiers de la recherche sur les droits fondamentaux), No 5, 2006, pp. 39-44; Neirinck C., y Martin, P.-M. "Un traité bien maltraité: à propos de l'arrêt Lejeune”, en JCP G (La Semaine Juridique. Édition Générale), 1993, p. 223; Rondeau-Rivier, M.-C., "La Convention des Nations Unies sur les droits de l'enfant devant la Cour de cassation: un traité mis hors-jeu”, en Dalloz, 1993. Chronique 203; Rongé, J.-L., "La Convention internationale relative aux droits de l'enfant: On avance ou on recule?”, en Journal du droit des jeunes, $\mathrm{N}^{\circ}$ 10/2004, pp. 9-15. 
Esta nueva adaptación se haría necesaria sobre todo por la aplicación restrictiva de la Convención por parte de los tribunales de fondo en Francia, influida por el criterio estricto que fijaría la Corte de Casación, en una primera etapa. El fallo Le Jeune ${ }^{28}$ evidenciaría la posición de la Corte de Casación que destacaba que del art. 4 de la Convención se desprendía que sus disposiciones creaban obligaciones solo para los Estados partes, por lo que no podían invocarse directamente por los particulares ante los tribunales ordinarios de Francia. En claro, la Corte sentaba que la aplicabilidad directa de la Convención no podía ser invocada por los justiciables, pues ella se refería a recomendaciones u obligaciones que se dirigían a los Estados partes y solo a ellos. En materia de autoridad parental, la Corte de Casación francesa seguiría el mismo criterio señalado confirmando, por ejemplo, lo resuelto por la Corte de Apelaciones de París en fallo de 9 de julio de 1991, que había dispuesto que la autoridad parental sería ejercida solo por la madre, fijando la residencia habitual de la menor con la progenitora que partía a instalarse en México, y expresando que el derecho de visita y alojamiento (droit de visite et d'bébergement) del

${ }^{28}$ Cass. civ. 1er, 10 marzo 1993, Pourvoi $\mathrm{N}^{\circ}$ 91-11.310, Bull. 1993 I, No 103 , p. 69. En el caso Le Jeune, el padre de la menor Frédérique (11 años), reconocida por ambos progenitores, luego de varios años de vida familiar común y producto de la separación sobrevenida, solicita a un juez de asuntos familiares que regule un régimen de visitas a su favor. En 1988 este juez especial ordena un informe social de la menor. Del informe social aparece el rechazo de esta para tener contacto directo y regular con su progenitor, ante ello el juez ordena un informe médico (psiquiátrico) acerca de las causas de la negativa y en caso de "serio rechazo" solicita pronunciarse acerca de si la ausencia de relaciones filiales resultaría o no conforme, en el corto y mediano plazo, al interés de la niña. El 21 de agosto de 1989, el juez teniendo a la vista los informes respectivos rechaza la demanda de visitas del padre. Alzado en apelación, la Corte de Apelaciones de Rennes, el 7 de diciembre de 1990, confirma la sentencia de primer grado. Recurriendo de casación el padre denuncia la manipulación de la madre y reclama que el informe médico al no haber audicionado a los padres y a la menor no puede decidir respecto del interés superior de la niña. Invoca la Convención de New-York en sus artículos 1, 3, 9 y 12 y la violación del art. 288 (en realidad se refería al art. 374) del Código Civil. La decisión de la Corte de Casación es la siguiente: “Atendido que las disposiciones de la Convención de Derecho del Niño, firmada a New-York el 26 de enero de 1990, no pueden ser invocadas ante los tribunales, esta Convención que no crea obligaciones sino para los Estados partes a ella, no puede ser aplicable directamente en derecho interno".

La Corte de Casación mantuvo un criterio diferente al del Consejo de Estado francés. Desde la entrada en vigor de la Convención este órgano administrativo superior buscó distinguir al interior de la Convención las disposiciones que eran de aplicación directa y las que no lo eran. Entre aquellas que no eran de aplicación directa, probablemente la decisión más conocida sea la que se expresó el 29 de julio de 1994 en el asunto llamado Préfet de la Seine-Maritime, donde el Consejo de Estado dispuso "que las estipulaciones del artículo 9 de la Convención relativa a los derechos del niño suscrita a New-York el 26 de enero de 1990 solo crean obligaciones entre los Estados sin abrir derechos a los interesados...", que en ese contexto los solicitantes "no pueden útilmente ampararse de ese compromiso internacional para demandar la nulidad de las resoluciones administrativas que los reconducen (expulsados de Francia) a la frontera". En sentido contrario, el Consejo de Estado siempre dejó claro su pronunciamiento acerca de la aplicación directa en Francia del artículo 16 relativo a la vida privada de los menores, la del artículo 8 relativo a la preservación de la identidad de los menores, la del artículo 12-2 relativo al derecho de ser oído el menor en todas las instancias administrativas y judiciales, la del artículo 37 referido a las condiciones de mantención en prisión de los menores y principalmente la del artículo 3-1 relativo a la primacía del interés superior de los niños.

El punto de convergencia entre estas altas jurisdicciones se habría de producir en el 2005, cuando la Corte de Casación abandona la doctrina del caso Le Jeune y decide que el artículo 3-1 de la Convención debe recibir aplicación directa por los órganos jurisdiccionales franceses en el orden interno. 
padre debía ejercerse solo en territorio mexicano, desoyendo la invocación que hacía el padre de la aplicación de la Convención ${ }^{29}$. Este criterio estrecho de la Corte de Casación evolucionaría una década después consagrando la aplicación directa de la Convención en el derecho interno francés ${ }^{30}$.

Es en ese contexto donde "la noción de interés del niño pasa a erigirse como la piedra angular de la autoridad parental: su condición, medida y fin" ${ }^{31}$, que en el primer tercio de la década del 90 se dictará una nueva ley ( $\mathrm{N}^{\circ}$ 93-22 de 8 de enero de 1993$)^{32}$ que colocaría a la autoridad parental conjunta como principio rector o esencial del derecho francés $^{33}$, confiriendo al niño (a), cualquiera sea su filiación, el derecho a crecer con su padre y madre. En caso de divorcio, a diferencia de lo que venía ocurriendo, el ejercicio en común de la autoridad parental pasará también a ser la regla general que solo podrá romperse en caso que lo exija el interés del niño (a), de manera que el juez recibirá el mandato de intervenir solo en el caso de desacuerdo entre los padres ${ }^{34}$. Tratándose de hijos no matrimoniales todavía, a pesar de la proclama del principio del ejercicio en común de la autoridad parental, se sigue subordinando esta al reconocimiento del menor por ambos progenitores dentro del año de su nacimiento y a la cohabitación de

${ }^{29}$ Cass. civ. 1er, 02 junio 1993, Pourvoi No 91-17487, Bull. civ. 1993 I, Nº 195, p. 135.

${ }^{30}$ Cass. civ. 1er, 18 de mayo de 2005, Pourvoi No ${ }^{\circ}$ 2-20.613, Bull. civ. I, No 212. Esta decisión está referida al caso de Chloé, una niña de padre francés y madre americana, que vivía con esta en Francia. La madre al decidir retornar a Estados Unidos se encuentra con la negativa del padre que solicita fijar en Francia la residencia de la menor de 11 años. Esta requiere ser oída por los tribunales de Francia en relación con la solicitud de su padre, enviando al efecto una carta al tribunal de alzada, la que es desoída. La Corte de Casación, al decidir anulando la sentencia, pone todavía más en relieve el cambio de criterio al establecer que la consideración primordial del interés superior del niño y el derecho a ser oído le imponían a los tribunales franceses tomar en cuenta la solicitud del niño, por lo que al no ser estimada (o rechazada por resolución fundada) la Corte de Apelaciones habría violado directamente los arts. 3-1 y 12-2 de la Convención. V. Courbe, P. "L'application directe de la Convention des Nations unies sur les droits de l'enfant", en Dalloz, 2006, Chronique 1487.

En una tercera etapa, desde 2005 hasta hoy, la Corte de Casación valida la referencia de los jueces de fondos a la Convención e incluso insta a estos a invocarla directamente ( $v$.gr. Cass. civ. 1er, 8 de noviembre de 2005, Pourvoi No 02-18.360; Cass. Civ. 1er, 13 de marzo de 2007, No 06-17.869 y No 06-12.655; Cass, Civ. 1er, 22 de noviembre de 2005, Pourvoi N $\mathrm{N}^{\circ}$ 03-17.912).

${ }^{31}$ Malaurie y Aynès, op. cit., p. 604.

${ }^{32}$ Ley N $\mathrm{N}^{\circ}$ 93-22 promulgada el 8 de enero de 1993 que modifica el Código Civil en relación con el estado civil, la familia y los derechos de los niños e instituye la judicatura de asuntos familiares (juge aux affaires familiales). Para una revisión del impacto que causa esta ley en la doctrina de la época: V. Boullez, C., "Les relations parents-enfants dans la loi du 8 janvier 1993: l'autorité parentale", en Gazette du palais, 17 de junio de 1993, pp. 828 y ss.; Le Mintiel, B., "Présentation de la loi No 93-22 du 8 janvier 1993 modifiant le Code civil relative à l'État civil, à la famille et aux droits de l'enfant et instituant le Juge aux Affaires Familiales", en Revue juridique de l'Ouest, 1994-1, pp. 1-31; Massip, J., "Les modifications apportées au droit de la famille par la loi du 8 janvier 1993, en Défrenois, 1993-1, p. 609; Rubellin-Devichi, J. "Une importante réforme en droit de la famille: la loi No 93-22 du 8 janvier 1993”, en JCP, 1993, éd. G, I, 3659.

${ }^{33}$ El carácter de principio rector o, en palabras de la Corte de Casación, de principio "esencial del derecho francés" se erige sobre la base de la igualdad de los padres en el ejercicio de la autoridad parental (C. Cass. $1^{\text {er }}$ civ, 4 de noviembre de 2010, $\mathrm{N}^{\circ}$ 09-15302, Bull. civ. I, $\mathrm{N}^{\circ} 218$ ).

${ }^{34}$ La Ley No $93-22$ modificaba el art. 287 del Code con el propósito que el ejercicio en común de la autoridad parental sea, en principio, mantenida. La redacción quedaría como sigue: L'autorité parentale est 
los padres posterior al segundo reconocimiento. Sin la concurrencia de esos presupuestos los progenitores no ejercerán automáticamente y en conjunto la autoridad parental, sino previa declaración común ante el juez de asuntos familiares.

Este nuevo paso conllevará, además, a que el legislador francés imponga al juez de asuntos familiares la exigencia de establecer para el menor de padres separados una residencia única (résidence habituelle) en casa de uno de sus progenitores no solo en ausencia de acuerdo entre estos sino, además, cuando así también lo exigiera el interés del niño (a). A partir de esta regulación, donde la noción de résidence babituelle concentrará todas las prerrogativas que integraban el contenido de la autoridad parental (garde, surveillance y éducation), se dará inicio a una nueva forma de articular las prerrogativas del padre no custodio, lo que traerá consigo el desarrollo al máximo de la noción de droit de visite et d'bébergement que, con el correr del tiempo, se extenderá al punto de disfrazar una residencia alternada para el menor ${ }^{35}$, lo que terminará por provocar la reacción del legislador a comienzos del primer decenio del nuevo milenio.

\section{LA CONSOLIDACIÓN DE LA EVOLUCIÓN DEL DERECHO DE LA AUTORIDAD PARENTAL EN LOS DOS PRIMEROS DECENIOS DEL SIGLO XXI}

El comienzo del nuevo milenio traerá en Francia nuevas regulaciones ${ }^{36}$ donde destacarán, por un lado, la modificación del concepto mismo de autoridad parental, en

exercée en commun par les deux parents. Le juge désigne, à défaut d'accord amiable ou si cet accord lui apparaît contraire à l'intérêt de l'enfant, le parent chez lequel les enfants ont leur résidence habituelle.

Si l'intérêt de l'enfant le commande, le juge peut confier l'exercice de l'autorité parentale à l'un des deux parents.

Les parents peuvent, de leur propre initiative ou à la demande du juge, présenter leurs observations sur les modalités de l'exercice de l'autorité parentale.

Como se aprecia, si el art. 287 bajo la ley de 1987 señalaba que la autoridad parental era ejercida sea en común por ambos padres...sea por uno de ellos... (l'autorité parentale est exercée soit en commun par les deux parents,... soit par l'un d'eux..., la nueva redacción nacida de la ley de 1993 marcará la diferencia en su redacción y señalará, por el inciso primero, que la autoridad parental es ejercida en común por ambos padres... (l'autorité parentale est exercée en commun par les deux parents....); y, por el inciso segundo, que si el interés del menor lo exige, el juez puede confiar el ejercicio de la autoridad parental a uno de los padres (Si l'intérêt de l'enfant le commande, le juge peut confier l'exercice de l'autorité parentale à l'un des deux parents). Luego, esta redacción será suprimida por la Ley N No 2002-305 de 4 de marzo de 2002, y el art. 287 del Code renviará pura y simplemente a los principios de derecho común del ejercicio de la autoridad parental contenida en los arts. 371 y siguientes del Code.

${ }^{35}$ V. CA. Lyon, 5 de octubre de 1993, JCP, 1994. II. 22231, nota Fulchiron, H.; CA. Paris, 10 de febrero de 1999, JCP, 1999. II. 10170, nota Garé. Bosse-Platière, H., "La légalisation de la résidence alternée", en JCP, 2002, I, p. 165; Reynaud, P., "Responsabilité des père et mère et résidence alternée", en AJ fam. (Actualité Juridique. Famille), 2002, N 133 y Schmitt, T., "Résidence alternée et quotient familial", en AJ fam. (Actualité Juridique. Famille), 2003, No 23.

${ }^{36}$ Ley N $\mathrm{N}^{\circ}$ 2002-305 promulgada el 4 de marzo de 2002 sobre la autoridad parental. Esta ley se dicta sobre la base, principalmente, de las proposiciones de la Comisión Dekeuwer-Défossez que se esforzará en configurar un derecho común de la autoridad parental haciendo desaparecer los estatutos distintos para hijos matrimoniales o no matrimoniales. En el segundo decenio destacarán la Ley No 2011-1862 promulgada el 13 de diciembre de 2011, modificada por la Ordenanza $N^{\circ}$ 2015-1288 publicada el 15 de octubre de 
donde se prescinde del señalamiento de los medios que se otorgan a los titulares para ejercerla, para concentrarse en los fines u objetivos que ella persigue (1); y, por otro lado, la integración, dentro de la regulación del Código Civil, de la residencia alternada que pondrá fin a la obligación de reconocimiento para el niño (a) de solo una residencia habitual con alguno de sus padres, como uno de los mecanismos jurídicos concretos para asegurar una efectiva coparentalidad (2). La eficacia de este último, sin embargo, está todavía en la etapa de evaluación de sus resultados.

\section{Un nuevo milenio marcado por una autoridad parental en función de sus fines y no en función de sus medios.}

Al término del siglo XX habíase ya superado, en el Derecho francés, el debate entre titularidad y ejercicio de la autoridad parental. La titularidad de la autoridad parental no había dejado de ser un efecto patrimonial y personal consiguiente al establecimiento de la filiación, por cuya virtud los progenitores adquirían un conjunto de prerrogativas y deberes sobre sus hijos (as), sin importar la forma en que esta filiación había sido establecida $^{37}$. En claro, la titularidad, salvo escasas excepciones, había dejado de ser materia de debate pues “suscita [ba] muy pocas dificultades en la práctica ${ }^{38 ” . ~ E l ~ e j e r c i c i o ~ d e ~ l a ~}$ autoridad parental concentraba, en cambio, el mayor número de discusiones judiciales y doctrinarias. Una expresión de la profesora Bruggeman es relevadora del escenario de la discusión a lo largo de la evolución del derecho francés a fines del milenio pasado: "si aquel que ejerce la autoridad parental es necesariamente titular de ella, el solo hecho de detentarla no significa necesariamente ejercerla..."39.

Esa era la constatación. Sin embargo, había relativo consenso en que la autoridad parental no se podía analizar binaria o disociadamente (titularidad vs. ejercicio), como tampoco podía ser analizada correctamente en relación con su contenido o a las prerrogativas que de ella derivaban. Ha quedado dicho, de la pluma de los profesores Terré y Fenouillet, cuando describen el contenido que la ley daba a la autoridad parental (residencia, cuidado y educación) en el art. 371-2 del Código Civil, que esta había sido, desde su origen, objeto de variadas críticas ${ }^{40}$. Antes ya, el profesor Simler ${ }^{41}$ había puesto de manifiesto la confusa noción de garde de l'enfant, uno de los componentes

2015 relativa a la simplificación y modernización del derecho de familia. También es necesario destacar la Ley N 2007-308 promulgada el 5 de marzo de 2007 relativo a la reforma de la protección jurídica de los mayores vulnerables que reorganizó las disposiciones del Código relativas a la administración legal de los menores y a la tutela (guarda).

${ }^{37}$ V. Rebourg, M., "Filiation et autorité parentale à l'épreuve des nouvelles configurations familiales", en Rev. Recherches familiales, 2010/1, No 7, pp. 29-44.

${ }^{38}$ Bruggeman, art. cit., (n. 9), p. 93.

${ }^{39}$ Ibidem.

40 Terré y Fenouillet, op. cit. (n. 6 y 14).

${ }^{41}$ Simler, Ph., "La notion de garde de l'enfant. Sa signification et son rôle au regard de l'autorité parentale”, en RTD civ., 1972, p. 685. El profesor Simler la definía, en sentido estricto, como el derecho de fijar el lugar de residencia del menor y de exigir que allí permaneciera efectivamente. Concluía que la garde 
del contenido legal de la autoridad parental. Los otros componentes tampoco gozaban de autonomía y parecía que los contornos de las nociones que componían la autoridad parental carecían de límites precisos.

En este escenario y como consecuencia de la imposición progresiva por el legislador, como principio, del ejercicio en común de la autoridad parental por ambos progenitores, se producirá una verdadera mutación en la naturaleza jurídica de la autoridad parental. Una nueva visión se impondrá, esta vez basado más en los fines que esta persigue que en el contenido o los medios que el legislador otorga a sus titulares para ejercerla, lo que también pondría nuevamente en evidencia una desadaptación del concepto de autoridad parental, lo que llevaría a reformularlo.

En efecto, el art. 371-1 del Código Civil, en la redacción que nace de la Ley No 2002-305 promulgada el 4 de marzo de 2002 sobre la autoridad parental, dispondrá que la autoridad parental constituye un conjunto de derechos y deberes cuya finalidad es el interés del hijo (inciso primero), agregando que la detentan y ejercen los progenitores hasta la mayoría de edad o la emancipación del hijo, con el objeto de velar por su seguridad, salud y moralidad, garantizar su educación y permitir su desarrollo, con el respeto debido a su persona (inciso segundo); y, concluyendo que los progenitores harán partícipes al menor de las decisiones que le conciernan, en función de su edad y grado de madurez (inciso tercero) ${ }^{42}$.

Así concebido, por esta nueva redacción, el derecho de la autoridad parental comienza a ser (re) entendido como un derecho-función ${ }^{43}$, para expresar con ello no solo que este se ejerce para proteger al menor, también para reafirmar la vocación parental natural de los progenitores, "titulares originarios y depositarios legítimos de la función parental", como lo expresa el profesor Cornu ${ }^{44}$. La autoridad parental pasa a ser un conjunto de

constituía el núcleo alrededor del que gravitaban y se ordenaban todas las otras prerrogativas de la autoridad parental, la esencia sobre la que esta reposa y que le confiere toda su eficacia.

${ }^{42}$ Art. 371-1. L'autorité parentale est un ensemble de droits et de devoirs ayant pour finalité l'intérêt de l'enfant.

Elle appartient aux parents jusqu'à la majorité ou l'émancipation de l'enfant pour le protéger dans sa sécurité, sa santé et sa moralité, pour assurer son éducation et permettre son développement, dans le respect dî̀ à sa personne.

Les parents associent l'enfant aux décisions qui le concernent, selon son âge et son degré de maturité.

${ }^{43}$ Bénabent, A., Droit de la famille, Montchrestien, París, 2010, p. 457. Hacemos presente que quien evoca por vez primera la noción de droit fonction es Louis Josserand (Josserand, L., De l'esprit des droits et de leur relativité. Théorie dite de l'abus des droits, Reimpresión de la 2a edición de 1939, Dalloz, 2006, 490 pp.), quien, en el contexto de su teoría sobre el abuso del derecho, clasifica los derechos subjetivos en "derechosfunción" y "derechos-poder". Los droits fonctions serían aquellos que son conferidos al individuo en el interés de otro, tal como el derecho de corrección, la potestad marital, los conferidos a los guardadores, etc., ejemplos vigentes a la época.

La expresión "(re) entendido" quiere señalar, en realidad, que desde la ley de 1970 la autoridad parental fue así concebida, con un derecho-función y de orden público. En efecto, el art. 376, creado precisamente por la Ley $\mathrm{N}^{\circ}$ 70-459 de 4 de junio de 1970 y vigente hasta hoy, dispone que "ninguna renuncia ni cesión de la autoridad puede producir efecto, si no es en virtud de una sentencia y en los casos que más abajo se señalan" (Aucune renonciation, aucune cession portant sur l'autorité parentale, ne peut avoir d'effet, si ce n'est en vertu d'un jugement dans les cas déterminés ci-dessous).

${ }^{44}$ Cornu, G., Droit civil-La famille, $9^{\mathrm{e} e ́ d ., ~ M o n t c h r e s t i e n, ~ P a r i ́ s, ~ 2006, ~ p . ~ 158 . ~ V . ~ T a m b i e ́ n: ~ F u l c h i r o n, ~}$ H., "L'autorité parentale rénovée", en Defrénois, 2002, p. 959; Mulon-Monteran, E., y Thouret, S., "La 
derechos y deberes, es decir, un conjunto de prerrogativas, que deben ser ejercidas no en el interés de su titular sino en el interés del niño $(a)^{45}$.

Corolario de esta evolución es que los Tribunales de fondo en Francia sostendrán que la autoridad parental constituye una función de orden público ${ }^{46}$ que tanto el padre como la madre deben ejercer, no pudiendo por consiguiente renunciar a ella ni delegarla en un tercero, salvo en los casos y condiciones previstos por la ley ${ }^{47}$, lo que no impedirá, claro está, el avance de la tendencia a la contractualización del derecho de familia ${ }^{48}$, permitiendo la celebración de pactos o acuerdos entre los padres en relación con el ejercicio de la misma, aunque siempre con pleno respeto al interés del menor y debidamente controlado por el juez en el proceso de homologación ${ }^{49}$.

Un derecho-función de orden público se caracteriza no solo por su incomerciabilidad e indisponibilidad, sin perjuicio de los acuerdos lícitos y homologados por el juez que convengan los progenitores, sino porque en su contenido están detalladas las misiones (droit misión) que se le asignan al padre y a la madre ${ }^{50}$. En concreto, un derecho que se define por sus fines y no por sus medios.

Esta nueva evolución de la autoridad parental, como una función o misión de orden público (velar por la seguridad, salud y moralidad del hijo (a), garantizar su educación y permitir su desarrollo, con el respeto debido a su persona), vendrá acompañada por dispositivos concretos que permitirán asegurar a los progenitores, y en particular, al padre no custodio, efectivamente un ejercicio conjunto de la autoridad parental.

nouvelle autorité parentale”, en RJPF (Revue juridique personnes et famille), 2002-4, pp. 12 y ss.; Vauvillé, V., "Du principe de coparentalité", LPA (Revue Les Petites Affiches), 2002, pp. 4 y ss.

45 Bénabent, A., Ibidem.

${ }^{46}$ TGI Versailles, JAF, 6 de abril de 2004, Dr. Famille, 2004, comm. 99, nota Murat P.

En honor a la verdad esta concepción no es enteramente nueva. Como se avanzó antes (V. n. 5), en su más tradicional concepción la patria potestad, como lo señalan los profesores Marcel Planiol y George Ripert (Planiol, M., y Ripert, G., Traité pratique de droit civil français, t. 1, Les personnes, por Savatier, R., LGDJ, París, 1925. V. También: Dabin, J., "Le contrôle de la puissance paternelle”, en Travaux de l'Association H. Capitant, Dalloz, 1947, p. 408 y ss.), ya había sido evocada en los trabajos preparatorios del Código Civil por Albisson, encargado de relatar el título "De la puissance paternelle" al cuerpo legislativo, expresando que la patria potestad no era más un derecho sino un poder, un medio de cumplir en toda su extensión un deber indispensable y sagrado.

${ }^{47}$ Art. 376 Código Civil francés, precit. (n. 42).

${ }^{48}$ V. Royer A.-M. "Autorité parental et contrat", in La contractualisation du droit de la famille, bajo la dirección de Fenouillet, D., y Vareilles-Sommières, P., Economica, Paris, 2001, 327 p.

${ }^{49}$ Art. 373-2-7 del Código Civil francés. Les parents peuvent saisir le juge aux affaires familiales afin de faire homologuer la convention par laquelle ils organisent les modalités d'exercice de l'autorité parentale et fixent la contribution à l'entretien et à l'éducation de l'enfant.

Le juge homologue la convention sauf s'il constate qu'elle ne préserve pas suffisamment l'intérêt de l'enfant ou que le consentement des parents n'a pas été donné librement.

V. Malaurie Ph., y Fulchiron, H., Droit civil, La famille, 4e ed., Defrénois, Lextenso, París, 2011, p. 610.

${ }^{50}$ Derechos que se extienden por aplicación de la Ley No 2013-404, de 17 de mayo de 2013, en virtud del art. 6-1 del Code civil, a las parejas del mismo sexo que han adoptado un niño (a) en conjunto o en el contexto de la adaptación del hijo del otro cónyuge. 


\section{Un nuevo milenio marcado por una autoridad parental con dispositivos concretos que aseguran una efectiva coparentalidad, a la espera de un balance de su implementación}

Otro de los efectos que traerá consigo en el nuevo milenio la imposición progresiva por el legislador, como principio, del ejercicio en común de la autoridad parental por ambos progenitores, será el esfuerzo desplegado por el legislador para incluir instrumentos concretos que aseguren una efectiva coparentalidad, más allá de la sola declaración de la letra de la ley, es decir, hacia la búsqueda de la efectividad de la colaboración parental, que es la que realmente incide en la búsqueda del equilibrio en el ejercicio de las facultades y deberes de los progenitores.

El principal instrumento jurídico que traerá el nuevo milenio en el derecho francés de la autoridad parental será el de la residencia alternada del menor en casa de ambos padres $^{51}$.

Prohibida bajo el imperio del art. 287 del Código Civil ${ }^{52}$ (versión 1993) que había optado por la noción de residencia habitual, y varias veces sancionada por el juez como contraria al interés del menor, había comenzado a imponerse por vía judicial en el último decenio del siglo XX, como consecuencia de la extensión del droit de visite et d'bébergement ${ }^{53}$. En el nuevo milenio, la résidence alternée, como expresión de la autoridad

${ }^{51}$ Respecto de la recepción por la doctrina francesa de la résidence alternée: ver, entre otros, Albiges, Ch., (Dir.), "La résidence alternée provisoire ordonnée dans l'intérêt de l'enfant", en Gazette du Palais, 15/05/2014, $\mathrm{N}^{\circ} 135$; Bazin, E., "Exercice en commun de l'autorité parentale et droit de visite du parent auprès duquel l'enfant ne réside pas", en Droit de la famille, $\mathrm{N}^{\circ}$ 1, enero 2012, comm. 9; Briand, L., "Résidence alternée et conflit parental", en AJF, 2011, pp. 570 y ss.; Colpart, I., "Quel avenir pour l'alternance des résidences des enfants de parents séparés?", en Droit de la famille, $\mathrm{N}^{\circ} 12$, diciembre 2014, étude 19; Gabriel, A., y Strugala, C., "La résidence alternée", en Gazette du Palais, 03/09/2005, No 246, pp. 4 y ss.; Guedon, J.-P., "La résidence alternée de l'enfant après la séparation de ses parents", en Petites Affiches, 03/09/2004, No 177, pp. 3 y ss.; Juston, C., "Le challenge de la résidence alternée", en Gazette du Palais, 21/01/2010, No 21, pp. 11 y ss.; Mestrot M., "Aspects consensuels et conflictuels de la résidence alternée dans la loi relative à l'autorité parentale", en Petites affiches, 13/08/2004, N 162, pp. 3 y ss.; Moulon, E., "La résidence alternée", en Gazette du Palais, 17/03/2012, N 77 , pp. 7 y ss.; Perrotin, F., "La résidence alternée, source de conflit", en Petites Affiches, 27/08/2015, No 171, pp. 3 y ss.; Thevenet-Montfrond, D., "L’hébergement alterné égalitaire des enfants en cas de crise familiale", en Rev. Lamy droit civil, $\mathrm{N}^{\circ} 35,2008, \mathrm{~N}^{\circ} 2862$.

${ }^{52}$ Este artículo disponía: "el juez no puede confiar el cuidado de los niños comunes alternativamente al padre o a la madre”. V. Cass. civ., 2 ${ }^{\mathrm{e}}, 21$ de marzo de 1983, pourvoi No 82-11.742, comm. Moussa T., Dalloz 1984, jurisp. pp. 53-55 y Dekeuwer A., JCP G (Juris-Classeur Générale), 1984, N²0163, donde la corte sostiene que aunque el art. $287 \mathrm{del}$ Code no prohíbe formal y expresamente la residencia conjunta, el juez de familia rechaza homologar la convención de los padres disponiendo que la residencia alternada sacrifica la estabilidad del menor; Cass. civ. 1er, 2 de mayo de 1984, RTD civ., 1984, p. 691, obs. Rubellin-Devichi (y en el mismo sentido Caas. civ., 2e, 20 de noviembre de 1985 pourvoi $\mathrm{N}^{\mathrm{o}}$ 84-16.104), donde la Corte dispone: "Vistos los artículos 287, 290 y 373-2 del Code Civil, y considerando, que resulta de la combinación de esos textos que, en caso de divorcio, el juez teniendo cuenta de los acuerdos suscritos entre los cónyuges puede confiar conjuntamente el cuidado y residencia al padre o la madre, resulta que no puede, en consecuencia, confiar alternativamente la residencia a ambos. V. Bigot, A., "Autorité parentale: L'article 374 alinéa 3 du Code civil interdit de fait la résidence alternée”, en Petites affiches, 03/07/2001, No 131, pp. 26 y ss.

${ }^{53}$ Un caso ejemplificador de esta tendencia es la decisión de la Corte de Apelaciones de París, de 10 de febrero de 1999 (JCP (Juris-Classeur Périodique), 1999. II., p. 10170; y Garé, T., "Conformité de 
parental conjunta, pasará a ser definitivamente consagrada por el legislador pudiendo ser decretada por el tribunal a requerimiento de ambos padres; de uno de ellos contra la voluntad del otro; o, incluso contra la voluntad de ambos, cualquiera sea la edad de los menores ${ }^{54}$.

En efecto, el art. 373-2-9, inciso $1^{\circ}$ del Código Civil francés, bajo la redacción nacida de la Ley $\mathrm{N}^{\circ} 2002-305$ de 4 de marzo de 2002, prevé que la residencia del menor puede ser fijada sea en alternancia en el domicilio de cada uno de los padres, sea en el domicilio de uno de ellos ${ }^{55}$. Los Tribunales comienzan rápidamente a consagrar esta

l'hébergement alterné à l'intérêt de l'enfant", en JCP No 40/1999, pp. 1781-1782) que confirmaba la sentencia que accedía a la residencia alternada por estimarla, en la especie, benéfica para el menor. En el sentido de asimilar la residencia alternada a un derecho de visitas y de alojamiento extendido: V. Cass. civ., $2^{\mathrm{e}}, 16$ de noviembre de 1994, pourvoi No 93-11.101 y CA Lyon, 5 de octubre de 1993, comm. Fulchiron H., JCP G (Juris-Classeur Générale), No 12/1994, pp. 115-118, donde la Corte dispone que "a falta de acuerdo entre los padres sobre la residencia habitual del menor, corresponde al juez determinarla. Manteniéndose el ejercicio de la autoridad parental en común, el juez acordará al padre un derecho de visita y alojamiento extendido". V. también: Bosse-Platière, H., "La légalisation de la résidence alternée”, JCP (Juris-Classeur périodique), 2002. I., pp. 165 y ss.; Reynaud, P., "Responsabilité des père et mère et résidence alternée", en AJ fam. (Actualité Juridique. Famille)2002/4, pp. 133-135 y Schmitt, T., "Résidence alternée et quotient familial, AJ fam. (Actualité Juridique. Famille), 2003/1, pp. 23-26.

${ }^{54}$ A pesar de esta regulación, esta nueva modalidad de ejercicio de la autoridad parental se adopta con menos habitualidad de lo que se cree. El Instituto Nacional de Estadísticas y Estudios Económicos de Francia (INSEE) publicó un dossier titulado "Residencia y pensión alimenticia de niños de padres separados: decisiones iniciales y evolución”. En una suerte de balance de 10 años desde que la ley de 4 de marzo de 2002 instauró la posibilidad de residencia alternada para los niños (as) en el domicilio de sus padres. El informe revela que este modo de ejercicio de la autoridad parental aumentó casi al doble pasando de $12 \%$ en 2003 a $21 \%$ en 2012 cuando ha tocado al juez decidir la residencia de hijos de padres separados. La résidence alternée es dos veces más frecuente en caso de divorcio de común acuerdo que en los otros casos de divorcio y en los de padres no casados. Para estos últimos el aumento fue de solo 3 puntos porcentuales fijándose en $11 \%$. En el universo total de procedimientos, la residencia alternada se acordó en $16 \%$ de las separaciones, involucrando 34.000 niños. Todo el incremento señalado se ha producido en detrimento del porcentaje de casos en que la madre mantenía la residencia de los menores, pues los casos en que son los padres a quienes les era otorgado el derecho exclusivo de residir con sus hijos se mantuvo en el tiempo (7\%). Sin embargo, la residencia de los menores con su madre sigue siendo mayoritaria, solo en 2012 fue decidida por los tribunales en el $75 \%$ de los casos. Por último, al cabo de dos años de divorcio, los padres han cambiado el modo de residencia de sus hijos en provecho de una residencia única con la madre (INSEE, "Résidence et pension alimentaire des enfants de parents séparés: décisions initiales et évolutions", diciembre 2015. Disponible en http://www. insee.fr/fr/ffc/docs_ffc/COUFAM15.pdf. Consultado el 05.08.2016. V. También Couard, J., "Le JAF et la garde alternée" en Droit de famille, $\mathrm{N}^{\circ} 3$, marzo 2015, p. 7.

55 Artículo 373-2-9 (nacido de la Ley $\mathrm{N}^{\circ}$ 2002-305 de 4 de marzo de 2002 y modificado par Ley No 2016-297 de 14 de marzo de 2016). "En aplicación de los dos artículos anteriores, la residencia del hijo podrá establecerse en el domicilio de cada uno de los progenitores de forma alternada, o bien en el domicilio de uno de ellos.

A solicitud de cualquiera de los progenitores, o en caso de desacuerdo entre ambos acerca de las modalidades aplicables a la residencia del hijo, el juez podrá dictar con carácter provisional la residencia alternada de este durante el período que decida. A la extinción de dicho período, el juez se pronunciará 
nueva regulación ${ }^{56}$, aunque no de manera automática y siempre considerando el interés del menor ${ }^{57}$.

A diferencia, por ejemplo, del derecho belga ${ }^{58}$ que introdujo la residencia alternada como modalidad privilegiada de residencia del menor, o del Derecho holandés ${ }^{59}$ que

definitivamente en torno a la residencia alternada del hijo en el domicilio de cada uno de los progenitores, o bien la residencia en el domicilio de uno de ellos.

Cuando la residencia del hijo se establezca en el domicilio de uno de los progenitores, el juez de familia se pronunciará en torno a las modalidades aplicables al derecho de visitas del otro progenitor. Cuando lo dicte el interés del hijo, dicho derecho de visitas podrá ejercerse en un espacio de encuentro designado por el juez.

Cuando lo dicte el interés del hijo o la entrega directa de este al otro progenitor suponga una situación de peligro para alguno de ellos, el juez organizará las modalidades aplicables de tal forma que la entrega presente todas las garantías necesarias. Podrá dictar que dicha entrega se lleve a cabo en un espacio de encuentro designado por él, o con la asistencia de un tercero de confianza o del representante de una persona jurídica cualificada".

V. Guillonneau M., y Moreau, C., La résidence des enfants de parents séparés. De la demande des parents à la décision du juge. Exploitation des décisions définitives rendues par les juges aux affaires familiales au cours de la période comprise entre le 4 juin et le 15 juin 2012, Rapport du Ministère de la Justice, nov. 2013, p. 5. Disponible en http://www.justice.gouv.fr/art_pix/1_rapportresidence_11_2013.pdf. Revisado el 17.08.2016.

${ }^{56}$ Entre otros, CA Aix en Provence, 6e, Section B, 4 de octubre de 2007, comm. Strugala, C., "Le risque d'indétermination de la notion de résidence alternée en cas de partage inégalitaire de l'alternance", en Bulletin d'Aix, $\mathrm{N}^{\circ}$ 1/2008, pp. 21-24, en donde la Corte aixois invocando el 373-2-9 del Code civil que no prescribe como condición para fijar la residencia alternada, un cierto tiempo de convivencia parecido para el padre al que tenía la madre con el menor, establece sin embargo que la distancia de los domicilios de ambos progenitores hace imposible una división igualitaria de los tiempos de presencia del menor en el domicilio de los padres cuando aquel esté en el período escolar. Confirma, sin embargo, la decisión que había fijado una semana por medio la residencia alternada para el menor atendido que la madre se encontraba en su período de descanso maternal. En el mismo sentido de no sancionar la decisión de conferir la residencia alternada, a pesar de lo alejado del domicilio de los padres V., entre otros, CA Paris, 5 de febrero de 2004, RG 2002/20281; CA Douai, 29 de enero de 2004, comm. Murat, P., "L'homologation des accords parentaux à propos de la résidence de l'enfant: le fond et la forme", en Droit de la Famille, No 10/2005, pp. 23-24; y Cass. civ. $1^{\mathrm{e}}$, 19 de septiembre de 2007, pourvoi $\mathrm{N}^{\circ}$ 07-12.116, comm. Murat, P., "La résidence en alternance préférée à un 'droit de visite élargi' en raison de la plus grande stabilité quotidienne pour l'enfant”, en Droit de la Famille, N $11 / 2007$, pp. 19-20.

${ }^{57}$ V. Cass. civ. $1^{\mathrm{e}}, 28$ de marzo de 2006, pourvoi $\mathrm{N}^{\mathrm{o}}$ 04-11.056; Cass. civ. $1^{\mathrm{e}}, 8$ de noviembre de 2005, pourvoi $\mathrm{N}^{\circ}$ 02-18.360, note Hauser J., en RTD Civ., N $\mathrm{N}^{\circ}$ 1/2006, pp. 101-103 y Boulanger, F., "Applicabilité directe de la convention de New York et intérêt supérieur de l'enfant”, en Dalloz, No 8/2006, pp. 554-557; Cass. civ. $1^{\mathrm{e}}, 28$ de octubre de 2003, pourvoi $\mathrm{N}^{\circ}$ 01-16.174; CA Paris, 3 de abril de 2003, RG 2002/06417 y CA Paris, 26 de marzo de 2003, RG 2002/12023, entre otros.

${ }^{58} \mathrm{El}$ art. 374, § 2, inciso $2^{\circ}$, del Código Civil belga dispone que à défaut d'accord, en cas d'autorité parentale conjointe, le tribunal examine prioritairement, à la demande d'un des parents au moins, la possibilité de fixer l'hébergement de l'enfant de manière égalitaire entre ses parents". Por su parte el art. $374, \S 2$, inciso $4^{\circ}$, precisa que: "si le juge choisit de s'écarter du modèle législatif, il doit spécialement motiver sa décision, en tenant compte des circonstances concrètes de la cause, de l'intérêt des enfants et, importante innovation, de celui des parents.

V. Leleu, Y.-H., Droit des personnes et des familles, $2^{\mathrm{e}}$ éd., Larcier, Bruylant, Bruxelles, 2010, pp. 703 y ss. Para un estudio comparado franco-belga V.: Gaumont-Prat, H., "La résidence alternée à l'épreuve du droit comparé (France-Belgique)", en Droit de la famille, $\mathrm{N}^{\circ} 7-8$, julio 2012, étude 15 . En el mismo sentido en Suecia (2000), España (2005), Italia (2006), Portugal (2009) y Rumania (2013).

${ }^{59}$ En Holanda una ley de 2009 previó el derecho para el menor a vivir y crecer con ambos padres de manera igualitaria, estableciendo una presunción de residencia alternada que solo puede ser destruida 
la estableció como presunción de modalidad de ejercicio de la autoridad parental, por nombrar solo dos estatutos europeos que la han incorporado en sus regulaciones, para el derecho francés la residencia en alternancia en el domicilio de ambos progenitores no constituye sino un mecanismo, entre otros, de ejercicio de la autoridad parental, aunque se presenta como la primera alternativa ofertada a los progenitores al momento de fijar la residencia del menor ${ }^{60}$.

La incorporación de este mecanismo de ejercicio de la autoridad parental no fue, sin embargo, pacífica. Contribuyó a ello, por una parte, que el legislador francés no quiso definir lo que entendía por residencia alternada, dejándole esta tarea al juez de familia; y por la otra, que se criticó que solo la exigencia de una minoría había propiciado el cambio y no se había producido este como respuesta a un imperativo de la realidad que así lo exigía 61 .

En efecto, el ejercicio en conjunto de la autoridad parental, sin este mecanismo novedoso ${ }^{62}$, había demostrado dificultades prácticas para lograr una colaboración parental efectiva, pero, innegablemente, había avanzado estableciendo las bases de un desarrollo doctrinario y jurisprudencial de nociones claves para una efectiva colaboración de los progenitores, como las nociones de "decisiones usuales" y "decisiones importantes",

en caso de peligro para el menor o cuando este es el objeto de un conflicto entre sus padres. V. Ancel, P., "La résidence alternée: panacée ou pis-aller?", en AJ fam. (Actualité Juridique Famille), 2015, pp. 213 y ss.

${ }^{60}$ Hacemos presente que el 17 de septiembre de 2013 con ocasión del examen del proyecto de ley por la igualdad de hombres y mujeres, bajo el título Dispositions visant à préserver l'autorité partagée et à privilégier la résidence alternée pour l'enfant en cas de séparation des parents (Projet de loi pour l'égalité entre les femmes et les hommes), $\mathrm{N}^{\circ} 717$, ingreso 2 julio 2013; Rapp. AN No 1380, 2013-2014, el Senado francés votó, contra la opinión del gobierno, una moción tendiente a privilegiar la residencia alternada como mecanismo de ejercicio de la autoridad parental, por cuya virtud se propuso reemplazar el actual inciso $2^{\circ}$ del art. 373-2-9 del Code civil por el siguiente: A défaut d'accord, en cas d'autorité parentale conjointe, le Juge examine prioritairement, à la demande d'un des parents au moins, la possibilité de fixer l'bébergement de l'enfant de manière égalitaire entre les parents.

${ }^{61} \mathrm{Al}$ menos las estadísticas que arrojan el informe de INSEE (V. n. 53), así parecen demostrarlo.

${ }^{62}$ La decisión de ejercer la autoridad parental mediante este mecanismo tiene su impulso, originaria y naturalmente, en los propios progenitores, pero la real novedad del derecho francés es que este puede ser impuesto por el Tribunal en caso de desacuerdo, y no solo a título provisorio, lo que constituye una advertencia cierta y concreta para el padre que quiera obstaculizarla irreflexiva e infundadamente, pues puede verse afectado sea por una fijación de la residencia habitual del menor en casa del otro padre o, como se dijo, de una residencia en alternancia por el propio juez, quien lo hará teniendo siempre presente los fines de la autoridad parental así como lo establece el actual art. 371-1 del Código Civil francés, es decir, velando por la seguridad, salud y moralidad del menor, garantizando su educación y permitiendo su desarrollo, con el respeto debido a su persona. La Corte de Casación francesa así lo ha confirmado en una sentencia de 14 de febrero de 2006 (Cass. civ. 1er, N 05-13.202, Bull. civ. I, N ${ }^{\circ}$ 65, comentada en JCP 2006. I. 199, obs. Bosse-Platière; RTD civ. 2006. 300, obs. Hauser y RJPF 2006. 27, obs. Eudier), disponiendo que cuando los padres no se acuerdan para poner en ejecución la residencia alternada y que el juez la impone, este no está obligado a decretarla con carácter provisorio o imponiéndola como período de prueba, pues el inciso $2^{\circ}$ del art. 373-2-9 del Code civil dispone que en caso de desacuerdo de los padres sobre el lugar de residencia del menor el juez "puede" y no "debe" disponer la residencia alternada del menor. En el mismo sentido Cass. civ., 1er, 19 de septiembre de 2007, No 07-12.116, comentada en Gazzette du Palais, 2008, No 328-330, p. 33, obs. Mulon. 
dibujando así -en cierto modo- contornos bien precisos del ejercicio conjunto de la autoridad parental.

En concreto, habíase asentado ya en Francia la idea que el ejercicio en común de la autoridad parental implicaba, en principio, requerir el acuerdo de los progenitores para cada decisión referida a los hijos (as). Por un lado, las decisiones acerca de actos usuales o cotidianos, es decir, siguiendo a la profesora Bruggeman ${ }^{63}$, en sentido positivo, aquellos actos benignos que se acostumbran ejecutar o realizar en la vida diaria; o, en sentido negativo, aquellos actos que no significan ninguna ruptura con el pasado del menor y que no comprometen su futuro, gozaban de una presunción de acuerdo (aunque solo respecto de terceros), que eximían a los padres de aportar la prueba del double accord respecto de ellas, con lo que el legislador facilitaba el ejercicio conjunto de la autoridad parental ${ }^{64}$. Por otro lado, tratándose de los actos no usuales o cotidianos ${ }^{65}$, la codecisión exigía un esfuerzo de cooperación entre los padres que materializaba el ejercicio conjunto de la autoridad parental. Sin ese esfuerzo de colaboración, las decisiones en caso de conflicto pasaban a ser tomadas por el juez de familia ${ }^{66}$.

Bajo este escenario de avances sostenidos en materia de colaboración parental, nivelando las prerrogativas del padre no custodio, para articular mejor el ejercicio de la autoridad parental conjunta, la introducción de la residencia en alternancia, por un

${ }^{63}$ Bruggeman, art. cit., (n. 9), p. 100. En el mismo sentido CA Aix-en-Provence, 28 de octubre de 2011, RG N N $^{\circ} 11 / 00127$, D. 2012. 2267, obs. Bonfils, P., y Gouttenoire, A. Para el profesor Cornu la noción de actes usuels de l'autorité parentale relativamente à la personne de l'enfant es una noción marco a las que el legislador contemporáneo recurre a menudo en derecho de familia: más que entregar una lista que será necesariamente incompleta, utiliza una categoría general, "un sobre”, donde el juez es el encargado de definir los contornos de la especie (Cornu, G., L’âge civil, in Mélanges Roubier, 1961, Dalloz, T. 2, p. 9).

${ }^{64}$ Art. 372-2 Code civil (nacido de la Ley No 70-459). "Respecto de terceros de buena fe, se reputa que cada padre ha actuado con el acuerdo del otro cuando realizase a título individual un acto usual (cotidiano) de autoridad parental en relación con la persona del hijo" (A l'égard des tiers de bonne foi, chacun des parents est réputé agir avec l'accord de l'autre, quand il fait seul un acte usuel de l'autorité parentale relativement à la personne de l'enfant).

${ }^{65}$ Para la Corte de Apelaciones d'Aix-en-Provence (fallo precit., n. 63) son de este tipo las decisiones que suponen el acuerdo de ambos padres, en razón de su carácter inhabitual o que por su incidencia particular en la educación y la salud del menor suponen una reflexión previa acerca de su mérito y justificación para llevarlas a cabo.

${ }^{66}$ Un Proyecto de Ley (Nº 371-2014 de 27 de junio de 2014), en actual discusión, cuyo propósito es seguir simplificando y facilitando la praxis de la résidence alternée, además de incluir en el inciso $1^{\circ}$ del art. 372 del Código Civil el derecho de información recíproco de los padres que ejercen la autoridad parental (Ils s'informent réciproquement de l'organisation de la vie de l'enfant et prennent ensemble les décisions qui le concernent), propone la introducción de nuevas definiciones y perímetros de las nociones de "actos usuales" y de "actos importantes" en un nuevo art. 372-1, donde se define un acto importante como aquel que rompe con el pasado y compromete el futuro del menor o que afecta a sus derechos fundamentales.

(Art. 372-1. Tout acte de l'autoritéparentale, qu'il ait un caractère usuel ou important, requiert l'accord de chacun des parents lorsqu'ils exercent en commun l'autorité parentale. Cet accord n'est pas présumé pour les actes importants.

Constitue un acte important l'acte qui rompt avec le passé et engage l'avenir de l'enfant ou qui touche à ses droits fondamentaux.

En cas de désaccord, le parent le plus diligent saisit le juge aux affaires familiales, en référé le cas échéant. Le juge statue selon ce qu'exige l'intérêt de l'enfant et en prenant en considération les éléments mentionnés à l'article 373-2-11.) 
lado, generaba el temor de transformar el ejercicio conjunto en un ejercicio alternativo o sucesivo de la autoridad parental y, como consecuencia, que ello trajera aparejado un retroceso en la colaboración parental, la que -en el límite- hasta se haría innecesaria. Reglas diferentes, ritmos distintos, en breve, mundos apartes, es lo que podría traer consigo la residencia compartida, si en los hechos ella se traducía en un ejercicio unilateral de dos autoridades parentales que se sucedían cada vez que el menor cambiaba de residencia.

Por otro lado, la experiencia demostraba ${ }^{67}$ también que la codecisión en todos los actos importantes a menudo se traducía en un bloqueo que aumentaba el contencioso entre los progenitores, lo que a fin de cuentas provocaba el atrincheramiento de los padres en sus posiciones, con el consiguiente perjuicio para los hijos (as). La residencia alternada solucionaba, en principio, estos problemas y otro número apreciable de contenciosos entre los progenitores, así como los que se suscitan en relación con el padre no custodio con la obligación alimenticia, la comunicación directa y regular, la vigilancia y la responsabilidad civil por los hechos del menor ${ }^{68}$, aunque mantenía otros de siempre

${ }^{67}$ Es vasto el número y la naturaleza de los conflictos que traía consigo la codecisión [v.gr. para la ejecución de actos médicos (Cass. civ. $1^{a}$ sala, 26 de enero de 1994, D. 1995, p. 226, note Choain, tratándose de una circuncisión del menor; Raymond, Guy, nota sentencia CA Nancy, 3 de diciembre de 1982, JCP 1983, II, p. 20081, en relación con la elección de un tratamiento médico determinado para el menor); para la práctica de credos o religiones diferentes (V. CA Riom, 13 de noviembre de 1933, Gaz. Pal. 1933, pp. 991; CA Metz, 13 agosto 1987, No 45-225, negando a la madre el derecho de cambiar la religión del menor; CA Poitiers, 4 de marzo de 2003, No 206667, censurando al padre por haber retirado al menor del grupo de scout católico, sin el acuerdo de la madre; o más recientemente, Cass. civ., $1^{\text {a }}$ sala, 23 de septiembre de 2015, No 14-23.724, D. 2015., pp. 1952, referido a un conflicto parental sobre el bautizo del menor), para el tipo de educación que reciba el menor (V. CA Montpellier, 30 de mayo de 1988, N ${ }^{\circ} 1988-11583$, sancionando a una madre que cambia unilateralmente al menor de un establecimiento religioso por uno laico; o más recientemente CA Douai, 28 de agosto de 2014, $\mathrm{N}^{\circ} 14-05205$, AJ fam. 2014, p. 556, obs. Bazin, dándole a un padre judío el derecho de oposición frente a la decisión de la madre de cambiar al menor a un colegio católico; y en el mismo sentido CA Paris, 18 de octubre de 1955, D. 1955, p. 766, para un padre protestante) entre otros], y la razón puede encontrarse en la constatación que la hace expresamente el grupo de trabajo respecto de la coparentalidad que, por encargo del gobierno francés, se interrogaba "sobre la oportunidad de definir los actos importantes y los actos cotidianos o usuales y de consignar en la ley los principios que permitan calificar ciertas decisiones de los padres como unos u otros. La distinción de estos actos, en el centro del funcionamiento cotidiano de la coparentalidad, no es conocido por los padres y conduce a numerosos procesos judiciales. La ausencia de definición de los actos importantes aparece entonces como fuente de dificultades para los padres y los profesionales del derecho (Gouvernement français, Direction des affaires civiles et du sceau y Direction générale de la cohésion sociale, Rapport sur les réflexions du groupe de travail sur la coparentalité "Comment assurer le respect de la coparentalité entre parents séparés”, enero 2014, p. 9). V. también Dionisi-Peyrusse, Amélie y Pichard, Marc, "Autorité parentale et stéréotypes de genre: la part du droit”, AJ fam. 2014, pp. 174 y ss.; Guineret-Brobbel Dorsman,Anne y Sire, Sylvie, "Maman dit oui, papa aussi ou les regrettables incertitudes de la présomption d'accord en matière d'exercice conjoint de l'autorité parentale", LPA 2003, pp. 5 y ss.

${ }^{68} \mathrm{La}$ pregunta que se ha formulado la doctrina francesa es si la residencia alternada en casa de ambos padres creará, en los jueces, un nuevo criterio de responsabilidad civil alternada según el lugar en el que el menor resida o, por el contrario, mantendrá un criterio de responsabilidad conjunta. La profesora Guttenoire, por ejemplo, cree que los tribunales optarán por la segunda solución (Guttenoire-Cornut, A., "La consécration de la coparentalité par la loi du 4 mars 2002”, en Droit de la famille, No 11/2002, p. 5. Por una responsabilidad 
difícil resolución, como los referidos al consentimiento para la ejecución de actos médicos no cotidianos ni obligatorios, como en el caso de una intervención quirúrgica mayor, o los que se suscitaban con la práctica de credos o religiones diferentes, o una educación política determinada.

Este escenario “confrontacional”, sin embargo, era y es, a nuestro juicio, más aparente que real. La idea que subyace, no debe olvidarse, es que la residencia en alternancia en casa de ambos progenitores sigue siendo ante todo un mecanismo de expresión del ejercicio conjunto de la autoridad parental. Esta es una y se ejerce en conjunto por ambos padres, como una misión de orden público. Siendo los padres los primeros llamados a ejercerla en el interés de los hijos (as) y no en el interés propio, la residencia en alternancia deberá propender a la consecución de ese interés y, so pena de desnaturalizarla, pudiendo incluso ser privados de ella, no podrán los padres transformarla en un ejercicio unilateral de dos autoridades parentales distintas que se sucedan cada vez que el menor cambia de residencia. Esto exigirá, en síntesis, y tanto más que antes, la necesidad de los progenitores de informar (se) y colaborar (se) recíprocamente del ejercicio de sus prerrogativas y deberes parentales. Si ello no sucede, el juez de familia podrá siempre intervenir restableciendo el interés del hijo (a), piedra angular de la autoridad parental: su condición, medida y fin.

Razones no se han hecho presente, hasta ahora, para desconfiar que esta nueva modalidad del ejercicio de la autoridad parental no siga el mismo exitoso camino de la evolución del derecho francés de la autoridad parental. La evaluación del éxito de este instrumento jurídico, sin embargo, todavía no ha sido hecha desapasionadamente.

\section{CONCLUSiOnes}

1. La evolución del derecho francés de las relaciones jurídico-familiares entre progenitores e hijos muestra una coherente, rápida y oportuna reacción del legislador frente a las constantes mutaciones de los modelos sociofamiliares. En poco más de cuatro décadas ha sabido responder con instrumentos jurídicos adaptados para cada época a las exigentes y cambiantes necesidades sociales.

2. Los distintos mecanismos, dispositivos o instrumentos judiciales que ha implementado el legislador para asegurar la concreción de la coparentalidad, parecen equilibrar debidamente los derechos de todos los intereses en juego, buscando el mejoramiento de la posición del progenitor no custodio, aunque siempre anteponiendo como eje principal el interés de los hijos (as).

3. La última respuesta del legislador para alcanzar una más efectiva e igualitaria coparentalidad, la residencia compartida, ha sido juiciosamente introducida como uno más de los mecanismos de ejercicio de la coparentalidad, a la espera que un

solidaria se postula el profesor Saluden (Saluden, M., "La responsabilité des parents n'est pas subordonnée à une faute du mineur (arrêts du 13.12.2002)”, en RJPF (Revue Juridique Personnes et Famille), No 5/2003, p. 20. 
nuevo balance se haga de su aplicación, lo que podría abrir la posibilidad de una nueva etapa en esta rica evolución.

\section{BiBLIOGRAFÍA}

Albiges, Ch., (Dir.), "La résidence alternée provisoire ordonnée dans l'intérêt de l'enfant", en Gazette du Palais, 15/05/2014, No 135.

ANCEL, P., "La résidence alternée: panacée ou pis-aller?”, en AJ fam. (Actualité Juridique Famille), 2015, pp. 213 y ss.

BAZIN, E., "Exercice en commun de l'autorité parentale et droit de visite du parent auprès duquel l'enfant ne réside pas", en Droit de la famille, No 1, enero 2012, comm. 9.

Bénabent, A., Droit de la famille, Montchrestien, París, 2010, p. 457.

Bigot, A., "Autorité parentale: L'article 374 alinéa 3 du Code civil interdit de fait la résidence alternée", en Petites affiches, 03/07/2001, No 131, pp. 26 y ss.

Bosse-Platière, H., "La légalisation de la résidence alternée", en JCP, 2002, I, p. 165.

Boullez, C., "Les relations parents-enfants dans la loi du 8 janvier 1993: l'autorité parentale", en Gazette du palais, 17 de junio de 1993, pp. 828 y ss.

Briand, L., "Résidence alternée et conflit parental", en AJF, 2011, pp. 570 y ss.

Bruggeman, M., "L'excercice en commun de l'autorité parental après séparation en France", en Osaka University Law Review, No 58, febrero 2011, pp. 93-106.

Brunetti-Pons, C., "L'exercice de l'autorité parentale face au pluralisme familial", en Dialogue 2004/3, No 165, pp. 7-22.

Bureau, D., "De l'application directe en France de la Convention de New York du 26 janvier 1990 sur les droits de l'enfant", en RCDIP (Revue critique de droit international privé), 2005, p. 679.

Capitant, H., Les grands arrêts de la jurisprudence civile, $9^{\mathrm{e}}$ éd. (por F. Terré e Y. Lequette), Dalloz, Paris, 1991, pp. 237-244.

Carbonnier, J., Sociologie juridique, Librairie Armand Colin, Paris, 1972, 320 pp.

Colpart, I., "Quel avenir pour l'alternance des résidences des enfants de parents séparés?", en Droit de la famille, $\mathrm{N}^{\circ} 12$, diciembre 2014, étude 19.

Cornu, G., Droit civil-La famille, $9^{\mathrm{e}}$ éd., Montchrestien, París, 2006, p. 158.

Couard, J., "Le JAF et la garde alternée”, en Droit de famille, $\mathrm{N}^{\circ} 3$, marzo 2015, p. 7.

Dabin, J., "Le contrôle de la puissance paternelle", en Travaux de l'Association H. Capitant, Dalloz, 1947, p. 408 y ss.

Deleury E., Rivet M. y Neault J.-M. "De la puissance paternelle à l'autorité parentale: Une institution en voie de trouver sa vraie finalité", en Les Cabiers de Droit (Revista de Derecho de la U. de Laval), vol. 15, $\mathrm{N}^{\circ} 4,1974$, pp. 779-870.

Dekeuwer-Défossez, F., "L’application de la Convention de New York sur les droits de l'enfant", (note sous Civ. 1er, 10 de marzo y 2 de junio de 1993), en Dalloz 1994. Sommaire 34; y "La Convention internationale des droits de l'enfant: quelles répercussions en droit français?", en CRDF (Rev. Cabiers de la recherche sur les droits fondamentaux), No 5, 2006, pp. 39-44.

Dumortier, T., "L'intérêt de l'enfant: les ambivalences d'une notion 'protectrice", en La Revue des droits de l'homme [En línea], No 3, 2013, pp. 2-13.

Fulchiron, H., "L’autorité parentale rénovée”, en Defrénois, 2002, p. 959.

Gabriel, A., y Strugala, C., "La résidence alternée", en Gazette du Palais, 03/09/2005, No 246, pp. 4 y ss. 
Gaumont-Prat, H., "La résidence alternée à l'épreuve du droit comparé (France-Belgique)", en Droit de la famille, $\mathrm{N}^{\circ} 7-8$, julio 2012, étude 15.

Guttenoire-Cornut, A., "La consécration de la coparentalité par la loi du 4 mars 2002", en Droit de la famille, $\mathrm{N}^{\circ} 11 / 2002$, p. 5.

Gouttenoire, A., y Fulchiron H., "Autorité parentale”, en Dalloz, Répertoire de droit civil, 2005 (actualizado a enero de 2016), $\mathrm{N}^{\circ} 14$.

Guillonneau M., y Moreau, C., La résidence des enfants de parents séparés. De la demande des parents à la décision du juge. Exploitation des décisions définitives rendues par les juges aux affaires familiales au cours de la période comprise entre le 4 juin et le 15 juin 2012, Rapport du Ministère de la Justice, nov. 2013, p. 5.

Josserand, L., De l'esprit des droits et de leur relativité. Théorie dite de l'abus des droits, Reimpresión de la $2^{\text {a }}$ edición de 1939, Dalloz, 2006, 490 pp.

Juston, C., "Le challenge de la résidence alternée", en Gazette du Palais, 21/01/2010, № 21, pp. 11 y ss.

Kunn, Thomas S., The Structure of Scientific Revolutions, The University of Chicago Press, Chicago, $2^{\mathrm{a}}$ ed., 1970.

Legeais, R., "Les ajustements égalitaires de l'autorité parentale", en Defrénois, 1988, art. 34243.

Leleu, Y.-H., Droit des personnes et des familles, $2^{\mathrm{e}}$ éd., Larcier, Bruylant, Bruxelles, 2010, pp. 703 y ss.

LE Mintiel, B., "Présentation de la loi No 93-22 du 8 janvier 1993 modifiant le Code civil relative à l'État civil, à la famille et aux droits de l'enfant et instituant le Juge aux Affaires Familiales", en Revue juridique de l'Ouest, 1994-1, pp. 1-31.

LoCRÉ, J.-G., La Législation civile, commerciale et criminelle de la France, ou Commentaire et complément des Codes français, T.7, Treuttel et Wurtz Libraires, París, 1827, p. 52.

Malaurie, Ph. y Aynès, L., La famille, $4^{\mathrm{e}}$ éd., Défrenois. Lextenso Editions, París, 2011, pp. 600-606.

Malaurie Ph., y Fulchiron H., Droit civil, La famille, $4^{\mathrm{e}}$ ed., Defrénois, Lextenso, París, 2011, p. 610 .

Massip, J., "Les modifications apportées au droit de la famille par la loi du 8 janvier 1993, en Défrenois, 1993-1, p. 609.

Mestrot M., "Aspects consensuels et conflictuels de la résidence alternée dans la loi relative à l'autorité parentale", en Petites affiches, 13/08/2004, No 162, pp. 3 y ss.

MorançAis-Demeester M.-L. y Nicolas-Maguin, M.-F., "Pouvoirs du juge et volonté des parents dans l'exercice en commun de l'autorité parentale prévu par la loi du 22 juillet 1987", en Dalloz, 1988, Chronique, pp. 307 y ss.

Monéger, "L'exercice conjoint de l'autorité parentale. Aperçu d'une réforme”, en RDSS (Revue de droit sanitaire et sociale), 1987, pp. 699 y ss.

Mulon-Monteran, E., y Thouret, S., "La nouvelle autorité parentale", en RJPF (Revue juridique personnes et famille), 2002-4, pp. 12 y ss., y "La résidence alternée", en Gazette du Palais, 17/03/2012, N 77 , pp. 7 y ss.

Neirinck C., y Martin, P.-M. "Un traité bien maltraité: à propos de l'arrêt Lejeune”, en JCP G (La Semaine Juridique. Édition Générale) 1993, p. 223.

Perrotin, F., "La résidence alternée, source de conflit", en Petites Affiches, 27/08/2015, No 171, pp. 3 y ss.

Planiol, M., y Ripert, G., Traité pratique de droit civil français, t. 1, Les personnes, por Savatier, R., LGDJ, París, 1925.

Rebourg, M., "Filiation et autorité parentale à l'épreuve des nouvelles configurations familiales", en Rev. Recherches familiales, 2010/1, No 7, pp. 29-44. 
Reynaud, P., "Responsabilité des père et mère et résidence alternée", en AJ fam. (Actualité Juridique. Famille), 2002, No 133.

Rondeau-Rivier, M.-C. "La Convention des Nations Unies sur les droits de l'enfant devant la Cour de cassation: un traité mis hors-jeu", en Dalloz, 1993, Chronique 203.

Rongé, J.-L., "La Convention internationale relative aux droits de l'enfant: On avance ou on recule?", en Journal du droit des jeunes, $\mathrm{N}^{\circ}$ 10/2004, pp. 9-15.

Royer A.-M., "Autorité parental et contrat", in La contractualisation du droit de la famille, bajo la dirección de Fenouillet, D., y Vareilles-Sommières, P., Economica, Paris, 2001, 327 pp.

Rubellin-Devichi, J. "Une importante réforme en droit de la famille: la loi No 93-22 du 8 janvier 1993", en JCP, 1993, éd. G, I, 3659.

SALUdEN, M., "La responsabilité des parents n'est pas subordonnée à une faute du mineur (arrêts du 13.12.2002)", en RJPF (Revue Juridique Personnes et Famille), No 5/2003, p. 20.

Savatier, R., L'Art de faire de lois. Bonaparte et le Code civil, Dalloz, París, 1927, pp. 30-31.

Simler, Ph., "La notion de garde de l'enfant (sa signification el son rôle au regard de l'autorité parental)", en RTD civ. (Revue Trimestrielle de Droit Civil), 1972, p. 685 y ss.

Schmitт, T., "Résidence alternée et quotient familial", AJ fam. (Actualité Juridique. Famille), $2003, \mathrm{~N}^{\circ} 23$.

Thevenet-Montfrond, D., "L'hébergement alterné égalitaire des enfants en cas de crise familiale”, en Rev. Lamy droit civil, $\mathrm{N}^{\circ} 35,2008, \mathrm{~N}^{\circ} 2862$.

Terré, F. y Fenouillet, D., Les personnes. La famille. Les incapacités, $7^{\mathrm{e}}$ éd., Dalloz, Paris, 2005, pp. 989-1015.

Vauvillé, V., "Du principe de coparentalité”, LPA (Revue Les Petites Affiches), 2002, pp. 4 y ss. 
